\title{
Lo viejo, lo nuevo y su absorción. Comentario a "Viejo y nuevo pragmatismo" de Susan Haack*
}

\author{
J. Miguel Esteban \\ Departamento de Filosofía \\ Universidad Autónoma del Estado de Morelos \\ cloquell@buzon.uaem.mx
}

\begin{abstract}
Resumen: En estas páginas retomo la discusión sobre Susan Haack: "Viejo y nuevo pragmatismo" (Diánoia 47) iniciada en este mismo volumen por Ramón del Castillo. En la primera sección abordo el tema de la autenticidad, la seriedad en oposición al carácter antiintelectual que Haack adscribe al neopragmatismo. En la segunda presento algunos argumentos de James y Dewey que respaldan la continuidad entre viejo y nuevo pragmatismo, para después aportar algunos elementos debidos a Hookway que hacen que el cuadro de la filosofía de Peirce resulte algo más complejo de lo que Haack sugiere en "Viejo y nuevo pragmatismo". A partir de ahí contrapondré algunas consecuencias de los pragmatismos de Dewey y Peirce para la filosofía social. Por último, en la tercera parte, matizo algunas afirmaciones de Haack sobre el pragmatismo de Quine e intento presentar una imagen moderada del neopragmatismo de Rorty, una actitud filosófica más acorde con una teoría deweyana de la investigación como la que, según Haack, Rorty ha abandonado de una vez por todas.
\end{abstract}

Palabras clave: conocimiento, Dewey, investigación, neopragmatismo

Ante todo, mi agradecimiento a Diánoia y a su director, Guillermo Hurtado, por darme la oportunidad de terciar en este debate, y a Ramón del Castillo por la gentileza de haberme enviado su cuidado artículo antes de su publicación. Celebro comprobar cierto parecido de familia entre las versiones del pragmatismo de Ramón del Castillo y la mía, aunque ello pueda hacerme redundante en algún punto de su prolija réplica. Esta posibilidad, unida a la brevedad obligada en esta sección de Diánoia, me lleva a centrarme sólo en algunos aspectos del mosaico que Susan Haack nos ofrece en "Viejo y nuevo pragmatismo" (Diánoia, vol. XLVI, no. 47, pp. 21-59), dejando que el lector se beneficie del análisis que del Castillo hace del resto del pragmatismo de Haack. Por mi parte, trataré de aportar alguna nueva tesela a ese mosaico y, de ser posible, sugeriré cómo reemplazar otras que resultan ya demasiado gastadas. Mis sugerencias girarán en torno al

\footnotetext{
* Este trabajo ha sido posible gracias al Proyecto CONACYT 33105-H, "Sentido y Vigencia del Pragmatismo en la Filosofía Contemporánea".
} 
pensamiento de John Dewey —quizá, como afirma Ramón del Castillo, el pragmatista menos estudiado en la obra de Haack. ${ }^{1}$

\section{Contingencia, autenticidad y seriedad}

Empezaré por el final. Haack concluye su artículo invitando al lector a no reducir la discusión a "cuáles son las variantes del pragmatismo que califican como auténticas". Pero la siguiente frase delata que es precisamente eso lo que ha estado haciendo a lo largo de su escrito: "es mejor [...] preguntarse, más bien, qué podemos aprender de la vieja tradición pragmatista y del naufragio intelectual de la nueva". ${ }^{2}$ A oídos informados puede sonar poco ecuánime llamar "naufragio intelectual" a la actual eclosión de estudios sobre pragmatismo en todo el mundo, y no sólo en algunos ámbitos posmodernistas legítimos de los estudios literarios. Bastará con que el lector curioso visite la página web de John Shook (http: //www.pragmatism.org) en la sección bibliographies, para comprobar la sorprendente variedad de neopragmatismos surgidos sólo en los últimos cuatro años. Variedad sobre todo de campos e intereses, legítimamente intelectuales en cuanto disciplinas académicas: desde el derecho, la teología, la ética y la estética, hasta las ciencias de la comunicación, la sociología y la antropología, las ciencias cognitivas, la gestión empresarial o, cómo no, la epistemología y la filosofía de la ciencia.

Imagino al menos dos posibles contrarréplicas. Cuando Susan Haack habla de "naufragio intelectual" podría referirse literalmente al naufragio del intelectualismo. Este naufragio, a su vez, podría ser entendido como el empobrecimiento del viejo pragmatismo, reducido a la doctrina del éxito por el éxito frente al éxito deliberado. ${ }^{3}$ Podría parecer que se trata de una buena pista. Haack llega a calificar a William James de antiintelectualista porque, a fin de cuentas, James siempre se rehusó a preocuparse por la Verdad en Abstracto. ${ }^{4}$ Por culpa de esa renuencia, cree Haack, los argumentos de James sucumben ante los de Moore y Russell, quienes acusaban a James de identificar de un modo "tan vulgar, tan típicamente estadounidense", 5 la verdad con la utilidad. Pero creo que Haack concede demasiado a Russell cuando afirma que, en vista del neopragmatismo antiintelectualista y

${ }^{1}$ Los textos de John Dewey citados en estos ensayos corresponden a la edición crítica de su obra completa publicada por la Southern Illinois University Press, bajo la dirección editorial de Jo Ann Boydston: The Early Works, 1882-1898, 5 vols.; The Middle Works, 1899-1924, 15 vols.; The Later Works, 1925-1953, 15 vols. Citamos con la abreviatura (EW, MW, LW) seguida por el volumen y la paginación en la edición crítica. MW.6:78, por ejemplo, indica John Dewey, The Middle Works, vol. 6, p. 78.

${ }^{2}$ S. Haack, "Viejo y nuevo pragmatismo" (en adelante VNP), p. 54.

${ }^{3}$ VNP, p. 52.

${ }^{4}$ VNP, p. 35.

${ }^{5}$ VNP, p. 34. 
revolucionario, "uno comienza a temer que Russell tuviera razón cuando predijo que el pragmatismo conduciría a la 'impiedad cósmica' o, en todo caso, al fascismo". ${ }^{6}$

En otras partes he insistido ${ }^{7}$ en que identificar el pragmatismo con el reductivismo del éxito por el éxito significa atribuir a los pragmatistas clásicos las mismas actitudes que trataban de combatir. Recientemente, Roy Eldridge nos ha recordado que, para un viejo pragmatista como John Dewey, era menos importante hacer que la inteligencia fuera práctica que hacer que las prácticas fueran inteligentes. ${ }^{8}$ Ya anteriormente Sidney Hook se había quejado de que la máxima pragmatista, según la cual todo esfuerzo intelectual dirigido a obtener nuevo conocimiento implicaba algún tipo de práctica o situación experimental, había sido ridiculizada y transformada en la tesis de que todo pensamiento tenía por único objeto la práctica. De ahí a la afirmación de que el pragmatismo era la lógica del capitalismo

${ }^{6}$ VNP, p. 23. Esta interpretación europea del pragmatismo como antiintelectualismo causó impacto entre otro tipo de intelectualistas, bien distintos de Russell el pacifista, pero cuya misma afición al absolutismo con respecto a la verdad — por diferente que fuera el contenido de esa Verdad Abstracta - condujo a posturas militaristas. En septiembre de 1940, Mortimer J. Adler señalaba a John Dewey como enemigo público número uno. Adler despreciaba el naturalismo de Dewey, esto es, su renuncia a cualquier tipo de filosofía primera con pretensiones de validez por encima de las ciencias particulares. De hecho, Adler tenía la firme convicción de que la prioridad absoluta de la filosofía sobre cualquier otra forma de saber anclaba la moral en el firme terreno de las verdades absolutas o incondicionales: "Si la moral abandona el dogma de las normas absolutas sólo nos quedará una certeza del mismo tipo que la que hoy prevalece en la física y en la química" (M. Adler, Philosopher at Large, p. 181). Según Adler, cuando pragmatistas y naturalistas señalan que todo lo que la filosofía puede lograr es una certeza de este tipo, una certeza relativa a condiciones y no una certeza metafísica última, privan a la moralidad de su fundamento absoluto y de su poder de aglutinación social: pragmatismo y naturalismo conducirían a una moral condicional y por lo tanto laxa y disoluta, incapaz incluso de enfrentarse al horror del fascismo. De hecho, en una conferencia titulada "Dios y los profesores", Adler acusaba a John Dewey y otros profesores "positivistas" de haber privado a la civilización occidental de los valores absolutos necesarios para hacer frente al nacional-socialismo de Hitler: "La amenaza más seria a la democracia es el positivismo de los profesores que domina todos los aspectos de la educación moderna y es el elemento central de corrupción de la cultura moderna. La democracia tiene mucho más que temer de la mentalidad de sus profesores que del nihilismo de Hitler" (citado por Dewey en LW.14:322]. Adler clamaba por que se expulsara a estos profesores universitarios como paso necesario para la resolución de los problemas que aquejaban a Estados Unidos. Por lo demás, Adler ya llevaba tiempo recomendando esa expulsión, como cuando llegó a convencer al Decano Hutchins de que despidiese de la Universidad de Chicago a algunos colaboradores de Dewey, entre ellos James H. Tufts, con quien escribió la Ética de 1894. Dewey, por el contrario, siempre defendió la significación social de la libertad académica, y el propio Russell, dicho sea de paso, se vio defendido por Dewey cuando ciertos jueces se opusieron a que ocupara su plaza como catedrático en la City University of New York por sus opiniones morales. Véase J. Miguel Esteban (comp.), John Dewey: Liberalismo y acción social y otros ensayos, pp. 207 y ss.

${ }^{7}$ Véanse, de J. Miguel Esteban, "Pragmatismo consecuente" y La crítica pragmatista de la cultura.

${ }^{8}$ R. Eldridge, Transforming Experience. Dewey's Cultural Instrumentalism, p. 5. 
mercantilista estadounidense había sólo un paso —paso que, por cierto, Russell ya había dado a comienzos de los años veinte del siglo pasado. ${ }^{9}$

En mi opinión, quitando algunos casos extremos, más propios del pragmatismo europeo de principios de siglo $\mathrm{xx}$ — perfectamente señalados por Haack, por cierto- que del pragmatismo del XXI, no parece haber neopragmatistas que conciban su filosofía como una reivindicación del éxito por el éxito - cosa que Haack, buena conocedora de la historia intelectual del pragmatismo, no puede ignorar. En consecuencia, no parece ésta una buena línea de respuesta. Ensayemos otra: quizá sea más correcto interpretar el neopragmatismo como un intelectualismo "naufragado" si lo hacemos en términos de la teoría del conocimiento del espectador. El antiintelectualismo neopragmatista sería así simple expresión de la heteronomía de lo teórico, entendida como Sidney Hook lo hacía: reconociendo la necesidad implícita en todo tipo de pensamiento dirigido a obtener nuevo conocimiento de algún tipo de práctica o situación experimental. Y es cierto que, gracias en parte al renacer del pragmatismo tras la prolongada hegemonía del positivismo lógico en Estados Unidos, la epistemología y la filosofía de la ciencia han imprimido un resuelto viraje hacia las prácticas en el estudio del conocimiento. Entre otros serios neopragmatistas orientados hacia el estudio filosófico de las prácticas podríamos hablar de Nicholas Rescher, mencionado una vez y de pasada en el artículo de Susan Haack, autor de libros de amplio influjo como The Primacy of Practice, o su excelente estudio Peirce's Philosophy of Science, o sus últimos libros Cognitive Pragmatism o Communicative Pragmatism. No abundaré en muchos más nombres, pero sí quisiera al menos mencionar a tres filósofos de la ciencia que se han declarado muy cercanos al pragmatismo, en el sentido de tomarse las prácticas en serio, y que de ningún modo caerían en la vulgaridad o la frivolidad que Haack atribuye al neopragmatismo: Larry Laudan, Ronald Giere e Ian Hacking. ${ }^{10}$

${ }^{9}$ B. Russell, "As a European Radical Sees It". La respuesta de Dewey fue bastante mordaz: "No hay que tomar demasiado en serio la sugerencia de que el pragmatismo es el equivalente intelectual del mercantilismo. Sería como interpretar que el neorrealismo inglés es un reflejo del carácter esnob de los británicos, o que la tendencia del pensamiento francés al dualismo expresa una supuesta disposición gala a tener amante además de esposa, o que el idealismo germánico es una manifestación de la capacidad alemana para elevar la cerveza y las salchichas hacia una síntesis superior con los valores espirituales de Beethoven y Wagner" (MW.13:308).

${ }^{10}$ Ramón del Castillo ha citado a Larry Laudan, autor bien conocido en México. Pero también en su último libro, Science without Laws, Ronald Giere reivindica reiteradamente el naturalismo y el pragmatismo de John Dewey, empleando algunas analogías ya empleadas por Dewey. Giere propone abandonar la noción semántica y formal de representación, conducente a paradojas como las que Hilary Putnam ha hecho célebres, para abrazar una noción más general de representación basada en la analogía con los mapas. Ian Hacking también reivindica los orígenes deweyanos de su pensamiento: "Mi propia opinión, a saber, que el realismo es un asunto de intervenir en el mundo, más que de representarlo en palabras y pensamiento, 
Otra de las consecuencias beneficiosas de ese viraje hacia las prácticas ha sido una nueva manera de concebir las relaciones entre filosofía de la ciencia y filosofía de la tecnología, algo en lo que Sergio Martínez y León Olivé $^{11}$ vienen insistiendo desde hace tiempo. Y creo que en este punto es imprescindible citar también la obra de un neopragmatista como Larry Hickman, quien ha puesto "el pragmatismo a trabajar". ${ }^{12} \mathrm{Si}$ por antiintelectualismo entendemos ese viraje hacia las prácticas, bienvenido sea. Pero el argumento de Haack da a entender algo más.

Haack parece adscribir la honestidad intelectual, el distanciamiento objetivo o la búsqueda desinteresada, la crítica impersonal y los valores de solidaridad, a la ciencia entendida exclusivamente como teoría. Pero eso es harina de otro costal. Un costal que, por lo demás, no hay que ser un pragmatista demasiado revolucionario para negarse a cargar. Baste recordar que, para John Dewey, en la práctica efectiva de la investigación científica, el reconocimiento abierto de los procesos de selección de datos es un importante requisito de honestidad intelectual, algo que hasta un neopragmatista redescriptivista como Richard Rorty podría admitir. Además, para Dewey, el distanciamiento crítico de la situación cualitativa de uso y disfrute es condición de la objetividad: "Ser intelectualmente 'objetivo' consiste en descontar y eliminar factores puramente personales en las operaciones con las que alcanzamos una conclusión."13 En mi opinión, desde una óptica deweyana, en ese distanciamiento y en el control público de los resultados es donde debe enmarcarse la debatida tesis de la neutralidad axiológica de la ciencia, y no el instrumentalismo puro y duro - la tesis según la cual la ciencia admite aplicaciones buenas o malas de acuerdo con fines predeterminados sobre los que no hay discusión racional posible- que ha empañado injustamente la reputación del pragmatismo durante toda su historia.

Un último comentario acerca de las virtudes que Haack atribuye a la búsqueda de la verdad en abstracto. Haack se une a Peirce en sus críticas morales a los pragmatismos "vulgares de la época":

ciertamente le debe mucho a Dewey" (I. Hacking, Representar e intervenir, p. 83). Otros pensadores pragmatistas que Ramón del Castillo echa en falta en el relato de Haack y que aquí incluyo, aunque someramente, son Nelson Goodman, Christopher Hookway, Nicholas Rescher y Sidney Hook.

${ }^{11}$ S. Martínez y E. Suárez, "Filosofía de la ciencia y la tecnología", manuscrito inédito; L. Olivé, El bien, el mal y la razón. Facetas de la ciencia y la tecnología. Con respecto al problema de la demarcación entre ciencia y tecnología, véase L. Olivé, "Ciencia y tecnología: distinciones externas".

12 L.A. Hickman, Philosophical Tools for Technological Culture. Putting Pragmatism to Work. Es de agradecer que, a diferencia de otros, Susan Haack no describa este viraje explícito en las posturas neopragmatistas en términos análogos a las imposturas denunciadas en el caso Sokal. Dicho sea de paso, el libro de Hickman, como el de Giere anteriormente mencionado, aciertan al juzgar el caso Sokal como algo que pone en entredicho ciertos constructivismos sociológicos. Algunos, no todos.

${ }^{13}$ LW.12:50. 
Peirce [...] se quejó de que los pragmatistas eran demasiado "vivaces": [...] "me parece una lástima que [el señor Schiller y los pragmatistas de hoy] permitan que la filosofía se vuelva tan llena de vida que acabe infectada por las semillas de la muerte, con nociones como [...] la mutabilidad de la verdad" $(6.485) .{ }^{14}$

Haack ha destacado aquí algo de sumo interés. Algunos pragmatistas italianos, pongamos por caso, mantuvieron una filosofía lo bastante vivaz para aguantar con optimismo lo que Peirce llama la mutabilidad de la verdad y unirse a futuristas como Marinetti y a nietzscheanos como Jünger, participando jovialmente en la aniquilación de la Primera Guerra Mundial. Pero ese nihilismo jovial, por emplear una expresión de Jünger, no es la única lectura ni la única consecuencia posible de admitir dicha mutabilidad de la verdad. No estoy seguro, pero Haack parece tener en mente a Richard Rorty y a su célebre lectura ironista de la contingencia como fuente de autopoiesis. En mi opinión, sea vivaz o no este ironismo, al menos resta otra lectura de tanto o mayor calado: la interpretación que Sidney Hook hace del pragmatismo en términos de reconocimiento trágico de la contingencia:

El pragmatismo [...] también expresaba cierto temperamento acerca de las opciones vitales a las que los humanos se enfrentaban cuando cobraban conciencia de cuáles eran las propuestas alternativas a las que éstas los comprometían. [El pragmatismo] hacía hincapié en la eficacia de los ideales y de las acciones humanas al mismo tiempo que en sus inevitables limitaciones. Trocó la promesa de las soluciones totales y de las salvaciones de una vez por todas en la de mejoras parciales. Lejos de abrazar fórmulas fáciles de reconciliación última de intereses en conflicto, reconocía también pérdidas parciales reales cuando los humanos arriesgamos la vida para obtener mejoras. No importa cuán inteligentes y humanas sean nuestras elecciones, insistía William James, "hay cosas que se pierden y gente que pierde". Vivimos en un mundo peligroso y serio, y, prosigue William James, "la misma seriedad que atribuimos a la vida significa que las pérdidas y las negociaciones forman parte ineluctablemente de ella, que hay verdaderos sacrificios y que siempre resta algo drástico y amargo al apurar la copa. ${ }^{15}$

Hook ha preferido citar a James para reforzar el vínculo pragmatista entre seriedad y contingencia. Pero creo que cabe hacer la misma lectura pragmatista del sentido trágico de la vida en la obra de Dewey The Quest for Certainty.

14 VNP, p. 45.

${ }^{15}$ Sidney Hook, Pragmatism and The Tragic Sense of Life, 1974, p. 5. 


\section{Pragmatismo y neopragmatismo}

Llegados a este punto, quizá sea legítimo preguntar por qué no contentarse con reducir el rubro "neopragmatismo" a los neopragmatismos que Haack critica, y en particular a lo que ella llama "rortysmo vulgar". Es una opción, claro. Pero no veo ninguna buena razón para excluir del neopragmatismo a autores que están escribiendo actualmente inspirados por temas y estrategias argumentativas del pragmatismo. Personalmente, no me preocuparía demasiado por la variedad del lote, que incluiría con toda justicia a la misma Susan Haack. Haack apela a James y a la Torre de Babel que significó el pragmatismo en sus inicios. Como señala Haack, ya Arthur Lovejoy hablaba de los trece pragmatismos. Pero no conozco ningún -ismo filosófico que no sufra o haya sufrido del mismo mal. Según creo, son las reconstrucciones filosóficas realizadas ex post facto las que suelen decidir la legitimidad de la calificación en cada caso.

Me parece mucho más fructífero explorar la vigencia de las herramientas del pragmatismo en nuevas situaciones con nuevos vínculos entre significado, valor, conocimiento y acción. En este sentido, podemos encontrar muy buenas razones dentro de la vieja tradición pragmatista para ampliar la extensión del término "neopragmatismo". La relación entre lo viejo y lo nuevo es una de las preocupaciones básicas de la concepción del conocimiento y de la investigación de lo que Haack llama viejo pragmatismo. Cito a William James, en traducción de Ramón del Castillo:

Nuestro conocimiento crece así a trozos, por zonas, y esas zonas se extienden como manchas de grasa. Pero las dejamos extenderse lo menos posible y conservamos inalterado nuestro conocimiento antiguo, nuestros antiguos prejuicios y nuestras antiguas creencias tanto como nos es posible [...]. Nuestro pasado empapa y tiñe la antigua masa, pero a su vez ésta también es matizada por lo que absorbe.

Y anteriormente: "Los 'trozos' pueden ser grandes o pequeños, pero el conocimiento nunca se desarrolla hasta cambiar en su totalidad: siempre hay un viejo conocimiento que permanece tal cual." James aplica estas tesis epistemológicas generales sobre la interacción entre lo nuevo y lo viejo con un ejemplo que viene muy al caso, dado el tema que estamos discutiendo: "El conocimiento que ustedes tienen del pragmatismo, supongamos, en este momento está creciendo. Más adelante, su desarrollo podría implicar una considerable modificación de las opiniones que ustedes tenían como verdaderas. Pero estas modificaciones tienden a ser graduales."16 Así las cosas, ¿qué tiene de malo que autores contemporáneos se acerquen al viejo pragmatismo con sus nuevas preocupaciones y que el viejo pragmatismo se vea gradualmente modificado?

16 W. James, Pragmatismo, pp. 150-151. 
En mi opinión, John Dewey aporta una razón más general para establecer esa continuidad gradual entre viejo y nuevo pragmatismo. Para Dewey, la investigación es el proceso de reconstrucción de la experiencia en la que se obra la unión de lo viejo y lo nuevo. La misma inteligencia se define en esos términos:

Hablando en términos generales, la inteligencia es precisamente el proceso de rehacer lo viejo uniéndolo a lo nuevo. Es la transformación de la experiencia pasada en conocimiento y la proyección de ese conocimiento en ideas y propósitos que anticipan qué puede suceder en un futuro. Ningún problema, sea personal o colectivo, simple o complejo, podrá solventarse sin seleccionar parte del material cognitivo acumulado en anteriores experiencias y poniendo en juego hábitos previamente formados. Pero el conocimiento y los hábitos tienen que modificarse de manera que se ajusten a las nuevas condiciones [...]. La labor que la inteligencia cumple en cualquier problema al que se enfrente una persona o una comunidad es efectuar una conexión operativa entre hábitos, costumbres, instituciones y creencias anteriores con las nuevas condiciones. ${ }^{17}$

Resulta difícil negar, hablando en los propios términos de Dewey, que las condiciones actuales -incluyendo las condiciones de las instituciones académicas - son bien distintas de las que vieron el surgimiento del primer pragmatismo. De ahí que el neopragmatismo, en todas sus variedades, sea un proceso de absorción selectiva del pragmatismo en el que no es de extrañar que proliferen multitud de transformaciones de acuerdo con un amplio abanico de propósitos. Como Mounce, Haack parece dividir estos propósitos en dos costales: "el honorable, que desciende de Peirce, y el deshonroso, que va de James y Dewey a Rorty et al." ${ }^{18}$ Como reitera Ramón del Castillo, el héroe de la historia narrada por Susan Haack es siempre C.S. Peirce, frecuentemente identificado como fundador del pragmatismo. ${ }^{19}$

La reconstrucción histórica de Haack recuerda bastante la que Imre Lakatos realizara de la filosofía de la ciencia pospopperiana, kuhniana, con

${ }^{17}$ LW.11:37, en traducción de J. Miguel Esteban, John Dewey: Liberalismo y acción social y otros ensayos, p. 89.

18 VNP, p. 23.

${ }^{19}$ H.S. Thayer y Peter Hare han objetado la afirmación de Rescher y Haack de que Peirce fue "el" fundador del pragmatismo, insistiendo a su vez en que James y Peirce fueron cofundadores. En su opinión, existen varias razones para cometer este error en la atribución de la paternidad. La más importante, desde luego, es que el propio James se refiere a Peirce como "el fundador". Pero, en opinión de Hare, esto se debía, en parte, a la generosidad de James hacia un amigo brillante que necesitaba con urgencia cierto reconocimiento, y en parte a que por aquel entonces concebía el pragmatismo exclusivamente como una teoría del significado. Para Hare, por el contrario, los principios de la epistemología voluntarista (la ética de la creencia, etc.) son tan centrales como la máxima pragmática, razón de más para considerar a ambos cofundadores del pragmatismo. Véase H.S. Thayer, Meaning and Action. A Critical History of Pragmatism. 
el supuesto naufragio del criticismo reformista (el falsacionismo) y la revolución "degenerativa" que supuestamente anulara el valor de la verdad para traer consigo "la conversión de la ciencia en religión". ${ }^{20}$ Como hemos visto, para Haack, Peirce es a fin de cuentas el único de los pragmatistas que contaba entre sus virtudes con un sincero y desinteresado amor por la ciencia. Lejos de mi intención está cuestionar toda la interpretación de Peirce que Haack, excelente conocedora de su obra, nos ofrece. Pero quizá sea útil apuntar algunos matices.

De hecho, por lo menos en "Viejo y nuevo pragmatismo", a veces da la impresión de que Susan Haack quiere salvar el pragmatismo de James y de Dewey por sus ocasionales adhesiones a una teoría epistémica de la verdad en cuanto creencia justificada en condiciones ideales como la que sostuvo Peirce: "la explicación peirceana del significado pragmático de 'verdadero' identifica la verdad con la opinión hipotética final que sería convenida si la investigación continuara indefinidamente". ${ }^{21}$ Creo que Hilary Putnam, por lo menos en algún momento de su proteico devenir filosófico, estaría de acuerdo con alguna versión de esta tesis. Y es cierto que podemos encontrar elogios a esta caracterización de la verdad en James, Dewey o Nelson Goodman. ${ }^{22}$ Haack reconoce que, en el caso de James y Dewey, ambos tienden a preferir "lo concreto a lo abstracto, la verificación real a la verificabilidad potencial, las verdades a la Verdad". ${ }^{23}$ En su Logic: The Theory of Inquiry, Dewey expuso explícitamente sus razones para preferir el término "aseverabilidad garantizada" a términos como conocimiento o creencia verdadera y justificada. Pero se diría que, para Haack, lo que parece conformar el trasfondo válido de todos estos pragmatismos es la idea peirceana de verdad como convergencia final en la creencia fijada por el método de la ciencia.

En un libro reciente, Christopher Hookway ${ }^{24}$ ha señalado algunos textos de Peirce que ofrecen una visión notablemente más compleja e histórica del desarrollo de su pensamiento. Según Hookway, en esos textos de la última década del siglo XIX, la noción disposicional de creencia que, como acertadamente señala Haack, Peirce toma de Bain, no desempeña función alguna en su teoría de la ciencia: "Sostengo — afirma Peirce- que la noción correcta y habitual de lo que se llama creencia no desempeña ningún papel en la ciencia." ${ }^{25}$ La ciencia pura, desinteresada, no tiene que ver con la creencia disposicionalmente entendida: con aquello sobre cuya base

${ }^{20}$ I. Lakatos, "La falsación y la metolodología de los programas de investigación científica", pp. 205-206.

${ }^{21}$ VNP, p. 30.

22 Véanse W. James, Pragmatismo, p. 184; J. Dewey, LW.12:343n, y N. Goodman, "Notes on a Well-Made World", p. 38.

${ }^{23}$ VNP, p. 39.

${ }^{24}$ C. Hookway, Truth, Rationality and Pragmatism.

${ }^{25}$ Collected Papers, 1.616-48. Citado por C. Hookway, op. cit., p. 21. 
uno está dispuesto a actuar. Para Peirce, la ciencia teórica es una búsqueda desinteresada de la verdad: el verdadero científico, el falibilista, no se casa con sus conclusiones. ${ }^{26}$ De hecho, ello le da en parte la razón a Haack en su interpretación de las virtudes intelectuales por las que Peirce dice apostar. Con todo, existe una tensión entre su defensa de esas virtudes y la descripción peirceana del método científico que Haack parece suscribir. Y se pregunta Hookway: "Si la aplicación del método científico no produce (o no debe producir) creencias en absoluto, es difícil ver cómo podemos concebir el método de la ciencia como el método para la fijación de la creencia." ${ }^{27}$ Irónicamente, si Hookway tiene razón aquí, Peirce podría formar parte de los pragmatistas eliminacionistas que tanto disgustan a Haack.

En parte, la tensión en cuestión radica, como bien señala Hookway, en la nítida distinción que Peirce trata de establecer entre teoría y práctica, una distinción tan marcada que, en mi opinión, haría de Peirce algo menos que un pragmatista reformista. Lo convierte en un conservador. Haack no alude a este hecho, pero Peirce siempre insistió en que no debíamos confiar en el método científico a la hora de resolver los problemas prácticos de vital importancia, sino confiarlos al instinto o al sentimiento. Hookway aborda este problema en toda su complejidad, pero pese a todos sus esfuerzos por conciliar el papel de la inteligencia y de los sentimientos en Peirce, me da la impresión de que algo resta en este autor de la dicotomía absoluta hecho/valor o razón/emoción. Y ésta es la raíz de las diferencias entre Dewey y Peirce, algo en lo que, en mi opinión, Haack no hace suficiente hincapié. ${ }^{28}$ Y cito a Dewey:

Mi último ejemplo tiene que ver con la división de la naturaleza humana en cierto número de compartimentos estancos. Uno de esos compartimentos supuestamente contendría la razón y todos los factores y capacidades para obtener conocimiento e ideas válidas. El otro consistiría en apetitos, impulsos, deseos, necesidades, en todo lo que se ha dado en llamar vida emocional en su sentido más amplio. La aceptación de las filosofías del pasado que erigieron esta división ha dado como resultado la formación de lo que desde el punto de vista técnico es probablemente el principal problema de la filosofía en el presente: la relación entre los hechos y los valores. ${ }^{29}$

Creo que Dewey tiene razón cuando afirma que dejar que el método experimental sustituya la fe o la tradición en el ámbito del conocer e impedir que lo haga en otros ámbitos significa permitir que los beneficios de ese método se instrumentalicen para perpetuar intereses de clase, prejuicios nacionales, raciales o de género en la conducción pública de los asuntos humanos.

${ }^{26}$ C. Hookway, op. cit., p. 22.

27 Ibid., p. 23.

28 VNP, p. 37.

${ }^{29}$ LW.14:323. 
Uno puede denominar a esta posición "pragmatismo revolucionario", pero yo creo que entronca con una antigua tradición liberal estadounidense. Por lo demás, resulta curioso que algunas versiones del neopragmatismo revolucionario que Haack denuncia sean más bien conservadoras en su sospecha ante cualquier intento de aplicar métodos experimentales en la esfera de la vida pública.

Aunque Haack no escatima elogios para la concepción de la democracia de Dewey, y reconoce la importancia que concedía a las relaciones entre filosofía social y filosofía de la educación, no duda en sugerir que "en retrospectiva, se advierte el peligro de que esto alentara la politización de la educación". ${ }^{30}$ Resulta algo chocante que alguien familiarizado con Democracy and Education nos advierta de ese peligro. Sobre todo porque, páginas antes, Susan Haack ha interpretado a Dewey correctamente cuando concibe la democracia como una forma de vida, más allá de lo estrictamente político, y también ha acertado al reconocer la deuda de Dewey con la psicología social de G.H. Mead, de cuya obra Haack ofrece un excelente resumen. La razón de fondo, en mi opinión, es que Haack se aferra demasiado a Peirce y no encuentra ningún argumento en Dewey que justifique que el conocimiento sea un agente de transformación ontológica: ${ }^{31}$ "Hay ciertos pedantes momificados que nunca han comprendido la verdad de que el acto de conocer un objeto real altera a éste. Son curiosos especímenes de la humanidad, y yo [Peirce] soy uno de ellos (5.555)." 32 No se trata de una cuestión fácil, ni quiera dentro de la scholarship sobre Dewey. ${ }^{33}$ En otros sitios he tratado de hacer una lectura desmistificadora de ese rasgo hegeliano del pensamiento de Dewey. ${ }^{34}$ Aquí me limitaré a señalar que si pensamos en la educación como instrumento de transformación del mundo social, la cosa no resulta tan complicada; así cabría entender la pregunta de James: "¿Por qué no ha de ser el cometido del pensamiento acrecentar y enaltecer la existencia, en vez de limitarse a reflejarla e imitarla?"35 En el fondo, lo que James y Dewey comparten aquí es el meliorismo. Yo diría que es ese meliorismo ontológico lo que diferencia la tesis pragmatista James-Dewey de que lo verdadero es una especie de lo bueno, de la versión platónica, abiertamente inmovilista.

30 VNP, p. 42

31 VNP, p. 29.

${ }^{32}$ VNP, p. 39.

${ }^{33}$ Véase al respecto J. Shook, Dewey's Empirical Theory of Knowledge and Reality.

${ }^{34}$ Véase J.M. Esteban, "La ciencia como tecnología en John Dewey", pp. 144 y ss.

${ }^{35}$ W. James, "Humanism and Truth", p. 457. 


\title{
3. El positivismo lógico, Quine y Rorty
}

Para Haack, los pragmatismos de Quine y Rorty son revolucionarios y eliminacionistas, y su carácter es más cercano al "estilo furiosamente antifilosófico del positivismo que al pragmatismo clásico". ${ }^{36}$ La historia de las relaciones entre empirismo y pragmatismo merece ser revisada con mayor detenimiento, más allá de la adopción de la máxima pragmática de Peirce en la semántica verificacionista del positivismo. ${ }^{37}$ Con todo, el papel que

\author{
${ }^{36}$ VNP, pp. $22-23$. \\ ${ }^{37}$ Véase Á. Faerna, Introducción a la teoría pragmatista del conocimiento, pp. 63 y ss.
} El interés por las relaciones entre las distintas variantes filosóficas del empirismo y del pragmatismo nace ya con la propia gestación del pragmatismo estadounidense durante el siglo XIX. Max Fisch, por ejemplo, ha señalado el peso que la filosofía de un seguidor de John Stuart Mill, el filósofo escocés Alexander Bain, tuvo en esa gestación. De hecho, aunque Charles Sanders Peirce era muy crítico con el nominalismo empirista, su máxima pragmática se inspira abiertamente en la noción de creencia de Bain. Por otra parte, sobre la deuda de William James con el empirismo, el consenso es mucho mayor. El mismo James bautizó a su pragmatismo como un empirismo radical. Robert Roth, por ejemplo, señala el origen humeano del tratamiento de la identidad personal en William James y el influjo de Bentham y Mill en su teoría psicológica. Por último, y pese a la gran disputa que John Dewey mantuvo con Bertrand Russell durante muchos años, el talante empirista de la filosofía de Dewey es también notorio. En "An Empirical Survey of Empiricisms", por ejemplo, Dewey formula con una claridad inusual el carácter empírico de su filosofía. Por lo demás, su Logic: The Theory of Inquiry entronca con una tradición metodológica que se remonta a Mill y a Bacon. En el siglo Xx, las relaciones entre el empirismo y el pragmatismo continuaron, pero fueron los empiristas lógicos quienes dirigieron su mirada hacia el pragmatismo estadounidense. Aunque nacido en Viena, el empirismo lógico alcanzó su apogeo en el segundo tercio del siglo pasado en Estados Unidos, debido en parte al exilio de pensadores como Hans Reichenbach y Rudolf Carnap. W.V.O. Quine y C. Morris, formados en una tradición pragmatista aún hegemónica en Estados Unidos hasta los años treinta, habían acudido al círculo empirista europeo para realizar sus estudios posdoctorales. Las aportaciones teóricas de Quine y Morris resultaron cruciales para la recepción estadounidense del empirismo, por su interpretación del llamado giro lingüístico. De hecho, los estudios clásicos sobre la absorción del pragmatismo por parte del empirismo lógico se han centrado principalmente en el criterio empirista de significación cognitiva, derivado de una interpretación de la máxima pragmática de Peirce en términos estrictamente semánticos. La percepción de las consecuencias del criterio empirista de significación cognitiva para la propia actividad filosófica imprimió un nuevo giro a las relaciones entre el pragmatismo y el empirismo. En 1951, Quine denunciaba dos dogmas del empirismo vinculados con el criterio de significación: la analiticidad, la verdad en virtud puramente del significado, y el reductivismo, la verificación entendida en términos atomistas. Según Quine, adoptar un pragmatismo más completo implicaba abandonar ambos dogmas y desdibujar las fronteras entre ciencia y filosofía que el empirismo lógico había trazado. En las décadas siguientes, un discípulo del positivista Hans Reichenbach, Hilary Putnam, se pasa a las filas del pragmatismo, denunciando al empirismo lógico como la gran manifestación intelectual del impacto de la ciencia en las concepciones modernas de la racionalidad, basadas en su opinión en la dicotomía hecho/valor. En esos años también, Paul Feyerabend se había atrevido a preguntar "¿Cómo ser un buen empirista?" tras haber renunciado a la racionalidad positivista. Por último, en los últimos años, una de las consignas del neopragmatismo de Richard Rorty es una pregunta para la que él presupone una respuesta negativa: “¿Queda algo digno de salvar en el empirismo?” Creo que el pragmatismo clásico, y en particular la obra de John Dewey, constituye una primera respuesta a la pregunta por el valor filosófico del empirismo. En un próximo artículo presento 
Quine concede a esta máxima y a Peirce en la formulación de la tesis holística de Duhem-Quine hacen de Quine algo más que un peirceano confuso, como afirma Haack. Aunque es cierto que el papel del pragmatismo en la filosofía de Quine es un asunto espinoso, ${ }^{38}$ tiendo a pensar que tiene que ver más con las tesis: (1) la infradeterminación empírica de la teoría y el holismo en la fijación de la creencia; y (2) la naturalización de la epistemología, que con la noción de género natural y su "afinidad" con el realismo escolástico de Peirce. ${ }^{39}$ Con respecto a (1), creo que tanto en "Two Dogmas" como en el primer capítulo de Word and Object o en The Web of Belief pueden detectarse algunas tesis cercanas al pragmatismo de William James, sobre todo por cuanto Quine extrae consecuencias holísticas de la imposibilidad de eliminar la contribución conceptual humana. La huella de la serpiente humana, según el dictum de James tan apreciado por Hilary Putnam, está por todas partes. Por otra parte, creo que Haack tiene toda la razón cuando afirma que se ha sobreestimado la aportación de Quine al debate analítico-sintético. Pero mientras que ella destaca el último párrafo de "Two Dogmas", yo también señalaría el primero, donde Quine une naturalización de la filosofía ("se desdibuja la frontera entre metafísica y ciencia natural") con cierta orientación hacia el pragmatismo. Años más tarde, en "Ontological Relativity", Quine remitiría explícitamente a John Dewey como antecedente de la naturalización de la epistemología.

Páginas atrás, Ramón del Castillo ha defendido con vigor el caso Rorty, y aunque su interpretación me parece acertada, no me encuentro tan cómodo como él ante los eslóganes de Rorty. De hecho, me atrevería a sugerir una máxima para leer a Rorty: "Sáltese los eslóganes meta-(anti)filosóficos y entre en materia." Y como viene insistiendo un neopragmatista hegeliano como Robert Brandom (a quien Haack ni siquiera menciona), hay en Rorty más materia filosófica de lo que parece. ${ }^{40}$

Creo que del Castillo acierta al entender el pragmatismo de Rorty principalmente como una forma de antiautoritarismo. Y aquí no cabe sino darle en parte la razón a Russell y a Haack en su acusación de impiedad cósmica: para Rorty, un buen pragmatista es en cierto modo un parricida. ${ }^{41}$ Aunque la noción de representación que critica Rorty es extremadamente pobre, ${ }^{42}$ creo que hay que interpretar el antirrepresentacionalismo que Haack de-

una interpretación pragmatista del empirismo a partir de las relaciones entre las filosofías de la ciencia de Otto Neurath, el empirista lógico que tanto influyó en Quine, y de John Dewey.

${ }^{38}$ Véase al respecto, por ejemplo, R. del Castillo, "Desde un punto de vista pragmático: Quine y sus críticos". Véase también J.M. Esteban, "Cordilleras, desiertos y ciénagas. Homenaje biobibliográfico a W.V.O. Quine".

${ }^{39}$ Véase VNP, p. 47.

${ }^{40}$ Véase, entre otros, R. Brandom, "Vocabularies of Pragmatism", pp. 156 y ss.

${ }^{41}$ Véase J.M. Esteban, "Cómo ser un buen pragmatista. Conversación con Richard Rorty".

${ }^{42}$ Véase, entre otros, A. Ibarra y T. Mormann, Representaciones en la ciencia. De la invariancia estructural a la significatividad pragmática, pp. 280 y ss. 
nuncia precisamente en esos términos. Rorty considera que la retórica de la representación es letal para el pragmatismo, "pues perpetúa una imagen de la relación entre personas y lo que no son personas que podemos llamar 'autoritaria': una imagen en la cual los seres humanos están sujetos a otro juicio que el de los seres humanos". 43

Con todo, Haack tiene parte de razón. No podemos ignorar que son muchos los que piensan que el pragmatismo surgió en 1979 con Philosophy and the Mirror of Nature - aunque no Rorty, dicho sea de paso. Y también es cierto que, como señalan Haack y otros muchos críticos de Rorty, más que absorción selectiva, Rorty ha hecho una cirugía plástica casi completa de James y Dewey para "exagerar su parecido con él mismo", ${ }^{44}$ y a veces con Wittgenstein, Nietzsche o Heidegger. Así, por ejemplo, creo que interpretar con Rorty Experience and Nature de John Dewey como un manual de terapia wittgensteiniana resulta un tanto disparatado. Pero, aunque son contadas, hay veces que Rorty acierta en la interpretación de Dewey. Para acabar, quiero poner de relevancia un texto de 1988 en el que puede matizarse la afirmación de Haack de que Rorty abandona la teoría deweyana de la investigación. ${ }^{45}$ Sobra decir que otros muchos textos le dan a ella la razón.

En "Inquiry as Re-Contextualization", Rorty concibe la investigación como reajuste o retejido de una red de creencias, entendidas al modo de Dewey, como hábitos para la acción. Puede ocurrir que una nueva creencia sea asimilada sin más, conectándola como un nudo más en la red. Pero cuando la nueva creencia instala una nueva disposición a la acción que entra en conflicto con las anteriores, se produce una tensión: la situación desequilibrada o indeterminada de la que nos habla Dewey en Logic: The Theory of Inquiry. Varios son los procedimientos de que disponemos para resolver el conflicto o transformar esa situación. Podemos identificar una antigua creencia aislada como responsable del conflicto e inhabilitar su modo de operación. Éste es el ideal reductivista, alcanzable sólo en casos muy específicos, relativamente simples. ${ }^{46}$ Por lo general, las revisiones afectan a secciones más amplias de la red. En ocasiones vale la pena encerrar la molesta creencia intrusa en una red subordinada de creencias creadas ex profeso, más periféricas, compatibles con las antiguas. Esta red subordinada puede interpretarse como un anillo doxástico, semejante al cinturón protector de hipótesis auxiliares del que nos habla Imre Lakatos. Pero a

${ }^{43}$ R. Rorty, Verdad y progreso, p. 179.

${ }^{44}$ VNP, pp. 51-52.

45 R. Rorty, "Inquiry as Re-Contextualization".

${ }^{46}$ Hay veces en que la creencia errónea es fácilmente identificable, como cuando basta con comprobar que alguna de las condiciones normales no se cumple. Nos cuenta el físico Anatole Abragam que en cierta época hizo colocar el siguiente cartel en la puerta de su laboratorio: "Antes de echar la mecánica cuántica a la basura, verifiquemos los fusibles por última vez." 
veces tantos remiendos en la periferia convierten la red en algo inservible, o como dice Quine, en un enorme rabo que menea a su perro. En ese caso, destejemos toda una sección de la red, borramos toda una serie de creencias, como cuando - apunta Rorty - los científicos dejaron de tener actitudes proposicionales hacia "Dios" o hacia el "flogisto".

Creo que Rorty está en lo cierto al reclamar como deweyana esta teoría holística de la dinámica de creencias, sobre todo cuando señala la gradualidad de la distinción entre hábito e investigación. Intentaré ilustrar este punto con algunos ejemplos. Supongamos que, a punto de sacar mi primer servicio en un partido de tenis, busco las bolas en mi bolsillo izquierdo, donde las suelo poner. No las encuentro allí, sino en el bolsillo derecho. Inmediatamente las coloco en el otro bolsillo, pues soy diestro, manejo la raqueta con la mano derecha y, a la hora de servir, elevo la bola con la izquierda. De hecho, es probable que el "error" se deba a que he recogido las bolas cuando tenía desocupada la mano derecha, esto es, entre juego y juego, cuando me proveo de bolas (si el servicio es mío) o se las lanzo a mi compañero (si le toca servir a él). El ejemplo es trivial, claro: nadie llamaría a esto una investigación. Pero consideremos la siguiente situación: la mujer que, por pura casualidad, averigua que su esposo tiene, además de la suya, otra familia, otra vida completa perfectamente simétrica. La incorporación de esa nueva creencia supone revisar muchas creencias del pasado - frecuentes prolongaciones de la jornada laboral, viajes inesperados, frecuentes confusiones de nombres, llamadas telefónicas a escondidas, súbitos descensos del presupuesto familiar-, pero, sobre todo, supone revisar también sus futuros planes y, como afirma Rorty, el sentido de su vida. Aquí hay algo más que hábito: hay investigación en el sentido de Dewey, transformación de una situación:

A medida que nos desplazamos a lo largo del espectro desde el hábito a la investigación —-desde la revisión instintiva de intenciones mediante el cálculo rutinario a la ciencia o la política revolucionaria- aumenta el número de creencias añadidas o sustraídas a la trama. En un determinado punto de este proceso empieza a ser útil hablar de recontextualización. Cuanto más amplios sean los cambios, más utilidad tendrá la noción de nuevo contexto. ${ }^{47}$

Susan Haack señala que Rorty sigue usando los términos "verdad", "investigación" y "justificación" despojándolos de todo lo que los arraiga en el mundo. ${ }^{48} \mathrm{Y}$ es cierto que Rorty vincula estos tópicos a la cuestión de un anclaje metafísico realista, una idea de la que, según Rorty, la filosofía contemporánea de la ciencia aún no se ha librado.

${ }^{47}$ R. Rorty, "Inquiry as Re-Contextualization", p. 94.

48 VNP, p. 52. 
Se trata de la idea de que la investigación consiste en hallar la naturaleza de algo que está fuera de la trama de creencias [... . Para los realistas, hay algún sentido en el que el objeto de investigación - lo que está fuera del organismotiene un contexto propio, un contexto privilegiado en virtud del objeto en vez del investigador. ${ }^{49}$

¿Avala ello la crítica de Susan Haack? La respuesta dependerá de qué concepto de creencia estemos manejando. Si optamos con Dewey por definir la creencia operacionalmente, como hábito de acción, la creencia integra tanto al organismo como al entorno y, por consiguiente, no hay nada "fuera" de la creencia cuando ésta opera: el objeto de investigación no es lo que está "fuera" del organismo. Es una situación que implica tanto a un organismo como a un entorno. Tampoco el contexto es del investigador. En ocasiones, el término recontextualización puede sugerir una actividad puramente subjetiva que no modifica el estado de las cosas, sino que cuando más proporciona un nuevo escenario, un nuevo decorado. Por eso quizá resulte más sobrio seguir a Dewey y hablar de situación y transformación de la situación en vez de contexto y recontextualización. Lo que se transforma es la situación del organismo-en-el-mundo. Dicho de otro modo: la situación ha de ser transformada porque ha surgido un conflicto con creencias anteriores, y hay que generar o eliminar una o varias creencias, cosa que implica tanto una transformación del organismo como del medio: de su situación-en-el-mundo. En Logic, Dewey sitúa en un seno biológico la investigación en cuanto transformación de una situación en el mundo. La situación-en-el-mundo viene integrada tanto por el organismo como por su entorno o medio ambiente. De hecho, ambos términos son codependientes: las condiciones de identidad del organismo no vienen dadas por la extensión de la membrana epidérmica, sino por sus pautas de acción, los hábitos de vida que su entorno posibilita. De hecho, nos dice Dewey, un organismo no vive en, sino en virtud del medio ambiente. ${ }^{50}$

Esta interpretación deweyana del mundo-en-situación como nicho ecológico es absolutamente ajena al mundo como correlato del esquema conceptual, un mundo que, en mi opinión, Rorty acierta a declarar felizmente perdido junto con el tercer dogma del empirismo. ${ }^{51}$ Aunque sí puede resultar compatible con la noción límite de mundo que Rorty dice tolerar, "aquellos objetos que, por el momento, la investigación no tiene en cuenta: aquellas planchas del barco que, por el momento, siguen en su sitio". ${ }^{52}$ Según creo, esta noción de mundo como conjunto de situaciones que no

${ }^{49}$ R. Rorty, "Inquiry as Re-Contextualization", p. 96.

50 "La diferencia no consiste en que el pez viva en el agua y el ave en el aire, sino que las funciones cracterísticas de estos animales son lo que son en razón del modo especial en que el aire y el agua entran a formar parte de sus respectivas actividades" (LW.12:32).

${ }^{51}$ Véase R. Rorty, Consecuencias del pragmatismo, cap. 1.

52 R. Rorty, "Inquiry as Re-Contextualization", p. 96. 
revisamos y que a su vez posibilitan la revisión de otras situaciones resulta prima facie aceptable, siempre que seamos falibilistas e insistamos en la continuidad entre hábito e investigación, de manera que nada nos asegura que esas creencias, por el momento estables, no vayan a ser objeto de ulterior investigación. Rorty insiste en que la representación no es el fin de la investigación y aduce que "las creencias no representan no-creencias". $\mathrm{Y}$, nuevamente, si partimos de una distinción ontológica entre la creencia y el objeto de la creencia, Rorty está en lo cierto. Pero, nuevamante, en el sentido pragmatista de creencia, la afirmación de Rorty es del todo inocua. Teniendo en cuenta la máxima pragmática, Rorty puede parafrasear la referencia al objeto de la creencia como referencia a los efectos prácticos que la creencia tendrá sobre nuestra conducta. Convengamos en llamar situación o contexto a una sección determinada de esos efectos. Investigar o recontextualizar no es sacar un objeto del contexto para examinarlo en sí mismo, independientemente de sus efectos, y ver qué nuevo contexto le conviene. "Todos los objetos", nos dice Rorty, "están ya siempre contextualizados". Lo cual es otra manera de decir que los objetos lo son por estar en situaciones, en el sentido que Dewey otorga a esta expresión. Las situaciones no son meros estados de cosas. Son estados de cosas en relación con un agente. Y cabría preguntarle a Susan Haack: ¿acaso no es ésta una descripción típica y legítimamente pragmatista de qué significa investigar?

Imagino que Susan Haack podría replicar que todo este empeño por encontrar un Rorty más sensato está condenado al fracaso. Y quizá también el propio Rorty se desentendería de ese antiguo yo y lo enterraría bajo un aluvión de argumentos etnocentristas o "tribalistas", para emplear el término que usa Haack. No escondo que mi empeño responde a la voluntad de contrarrestar el tópico de la perniciosa influencia de Richard Rorty sobre el pragmatismo serio, una muletilla tan extendida que está invitando a muchos a eximirse de la lectura de su obra. Una lectura que, como la de la obra de Haack, encuentro particularmente motivadora para todos los que estamos interesados en el pragmatismo.

\section{BIBLIOGRAFÍA}

Adler, Mortimer, Philosopher at Large, Macmillan, Nueva York, 1943.

Brandom, Robert, "Vocabularies of Pragmatism", en R. Brandom (comp.), Rorty and His Critics, Blackwell, Londres, 2000, pp. 156-183.

Castillo, Ramón del, "Desde un punto de vista pragmático: Quine y sus críticos", en

L. Arenas, A. Jiménez y J. Muñoz (comps.), El retorno del pragmatismo, Trotta, Madrid, 2000.

Dewey, John, The Early Works, ed. Jo Ann Boydston, Southern Illinois University Press, Carbondale, 1882-1898, 5 vols.

—- The Later Works, ed. Jo Ann Boydston, Southern Illinois University Press, Carbondale, 1925-1953, 15 vols. 
Dewey, John, The Middle Works, ed. Jo Ann Boydston, Southern Illinois University Press, Carbondale, 1899-1924, 15 vols.

Eldridge, Roy, Transforming Experience. Dewey's Cultural Instrumentalism, Vanderbilt University Press, Nashville/Londres, 1998.

Esteban, J. Miguel (comp.), "Cómo ser un buen pragmatista. Conversación con Richard Rorty”, Debats, no. 61, 1997, pp. 100-106.

—_, "Cordilleras, desiertos y ciénagas. Homenaje biobibliográfico a W.V.O. Quine", Crítica, vol. 33, no. 97, 2001, pp. 85-111.

—_, John Dewey: Liberalismo y acción social y otros ensayos, Alfons el Magnanim, Valencia, 1996.

__ , "La ciencia como tecnología en John Dewey", Diánoia, vol. XLV, no. 45, 1999, pp. 133-155.

— L L L crítica pragmatista de la cultura, Universidad Nacional de Costa Rica/Prometeo, Heredia, 2001.

—_,"Pragmatismo consecuente", estudio introductorio de John Dewey: Liberalismo y acción social y otros ensayos, pp. 7-46.

Faerna, Ángel, Introducción a la teoría pragmatista del conocimiento, Siglo XXI, Madrid, 1994.

Goodman, Nelson, "Notes on a Well-Made World", Of Mind and Other Matters, Harvard University Press, Cambridge, Mass., 1984.

Hacking, Ian, Representar e intervenir, trad. Sergio Martínez, Instituto de Investigaciones Filosóficas-UnAm/Paidós, México, 1997.

Hickman, Larry A., Philosophical Tools for Technological Culture. Putting Pragmatism to Work, Indiana University Press, Bloomington, 2001.

Hook, Sidney, Pragmatism and the Tragic Sense of Life, Basic Books, Nueva York, 1974.

Hookway, Christopher, Truth, Rationality and Pragmatism, Oxford University Press, Oxford, 2000.

Ibarra, Andoni y Thomas Mormann, Representaciones en la ciencia. De la invariancia estructural a la significatividad pragmática, Ediciones Del Bronce, Barcelona, 1997.

James, William, "Humanism and Truth", Mind, vol. XIII, 1904, pp. 457-477.

—, Pragmatismo, trad. Ramón del Castillo, Alianza, Madrid, 2000.

Lakatos, I., "La falsación y la metodología de los programas de investigación científica", en I. Lakatos y A. Musgrave, La crítica y el desarrollo del conocimiento, Grijalbo, Barcelona, 1981, pp. 205-343.

Martínez, Sergio y Edna Suárez, "Filosofía de la ciencia y la tecnología", manuscrito.

Olivé, León, El bien, el mal y la razón. Facetas de la ciencia y la tecnología, Universidad Nacional Autónoma de México/Paidós, México, 2002.

—_ "Ciencia y tecnología: distinciones externas", Theoría, segunda época, no. 56, febrero-septiembre de 1987, pp. 323-344.

Rorty, Richard, Consecuencias del pragmatismo, trad. J. Miguel Esteban, Tecnos, Madrid, 1996.

—_, "Inquiry as Re-Contextualization", Objetivism, Relativism and Truth, Cambridge University Press, Cambridge, 1991, pp. 93-110.

__ Verdad y progreso, trad. Ángel Faerna, Paidós, Barcelona, 2000. 
Russell, Bertrand, "As a European Radical Sees It", Freeman, no. 4, 1922, pp. 608610.

Shook, John, Dewey's Empirical Theory of Knowledge and Reality, Vanderbilt, Nashville, 2000.

Thayer, H.S., Meaning and Action. A Critical History of Pragmatism, Hackett, Nueva York, 1968.

Recibido el 19 de junio de 2002; aceptado el 23 de julio de 2002 